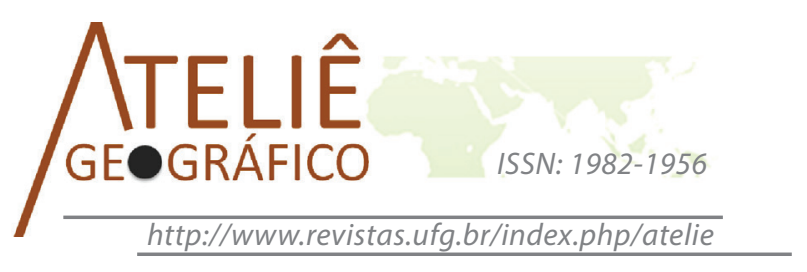

\title{
A paisagem cultural: multiplicidade interpretativa e políticas de preservação
}

\author{
The Cultural Landscape: interpretive multiplicity and \\ preservation policies
}

\section{El Paisaje Cultural: multiplicidad interpretativa y políticas de preservación}

\author{
Margareth Afeche Pimenta \\ Universidade Federal de Santa Catarina \\ afeche@arq.ufsc.br
}

\begin{abstract}
Resumo
Enquanto privilegiam ambientes tradicionais em nível mundial, no Brasil as interpretações acerca das paisagens culturais são variadas e, se por um lado, enriquecem o debate sobre os bens a serem valorizados, deixam escapar sem proteção setores socialmente fragilizados, mas ricos culturalmente, que deveriam ser foco de políticas de preservação específicas. Para além dos bens materiais, a paisagem cultural coloca novas questões que talvez possam ser precisadas a partir das diversas significações que o termo cultura foi adquirindo ao longo de sua história, não somente para direcionar as práticas de preservação, mas também para inseri-las numa visão maior de projeto societário.
\end{abstract}

Palavras-chave: paisagem cultural; cultura; patrimônio

\begin{abstract}
While favoring traditional environments in the world, in Brazil the interpretations about the cultural landscapes are varied and If on the one hand enrich the debate on the goods to be valued, they let it slip away without protection sectors socially weakened, but culturally rich, that should be the focus of specific preservation policies. Apart from material goods, the cultural landscape puts new issues that maybe can be specified from the various meanings to the term culture was acquired throughout its history, not only to direct preservation practices, but also to insert them into a larger vision of society project.
\end{abstract}

Keywords: cultural landscape; culture; heritage 


\begin{abstract}
Resumen
Al mismo tiempo que favorecen ambientes tradicionales en todo el mundo, en Brasil son muy variadas las interpretaciones sobre los paisajes culturales $\mathrm{y}$, si por un lado, enriquecen el debate sobre los bienes a ser valorados, dejan escapar sin protección sectores socialmente debilitados, pero culturalmente ricos, que deberían ser el foco de políticas específicas de conservación. Además de los bienes materiales, el paisaje cultural pone nuevos temas que tal vez pueden ser especificados por los diversos significados que el término cultura fue adquiriendo a lo largo de su historia, no sólo para dirigir las prácticas de conservación, pero también para insertarlas en una visión más amplia de uno proyecto de sociedad.

Palabras-clave: paisaje cultural; cultura; patrimonio
\end{abstract}

\title{
Políticas patrimoniais e ambiguidades da paisagem cultural.
}

Após duas décadas de seu estabelecimento como política de preservação patrimonial, a paisagem cultural apresenta resultados bastante desiguais em todo o mundo. A distribuição espacial da preservação patrimonial apresentou bastante variação, mas também as características do que foi considerado como objeto de proteção. Vales, terraços, montanhas sagradas, parques, ocupação das costas italianas, jardins renascentistas, vinícolas, bacias mineiras, sítios arqueológicos estão entre os exemplares até agora escolhidos como patrimônio mundial paisagístico. A representação da diversidade mundial merece destaque, quando tendências contraditórias disputam entre as particularidades locais e a homogeneização de valores universais.

No Brasil, o debate sobre as paisagens culturais aparece de forma menos definida. Em seu sentido amplo, toda a paisagem pode ser considerada cultural, já que é resultado de processos civilizacionais específicos que deixam suas marcas de forma mais ou menos duradoura. A precisão do significado cultural, acoplado à paisagem, talvez seja o elemento determinante quando se trata da definição de políticas de preservação.

A paisagem que se pode perceber, atualmente, representa o resultado de uma acumulação desigual de tempos históricos (SANTOS, 1982). Existem heranças que permanecem no presente, mas nem todas podem ser consideradas de valor patrimonial, ou seja, passíveis de um procedimento de valorização e de preservação. Aqui reside o problema central quando se trata da paisagem cultural, porque envolve, além do bem material, a proteção conjunta das relações históricas estabelecidas entre homem e ambiente. Desta forma, somente a definição geral de paisagens, como formas resultantes da ação humana, não pode dar conta do processo seletivo das ações preservacionistas. Tampouco a existência da relação homem-natureza que se perpetua em determinado local torna-se capaz de estreitar o filtro do ajuste patrimonial. A chave da questão para a depuração do arcabouço eletivo em termos patrimoniais talvez possa ser encontrada na especulação dos diversos sentidos atribuídos à cultura. Se a polifonia do termo cultura resulta, de fato, da riqueza da complexidade das sociedades concretas, ela pode vir a prejudicar a efetividade da ação pública em termos de aplicação de recursos, sempre 
escassos. As escolhas devem ser precisas, pois podem postergar ações que se tornam irreparáveis no decorrer tempo.

A dinâmica do processo de acumulação capitalista conspira contra as medidas de proteção patrimonial, sobretudo em países com fraca institucionalidade. Os processos de renovação das áreas rurais ou urbanas não costumam poupar as formas e os lugares tradicionais, considerados obstáculos ao desenvolvimento econômico. O tempo e a escassez na destinação dos recursos estatais atentam, portanto, contra a permanência de áreas consideradas economicamente arcaicas. A riqueza cultural deveria ser, portanto, o único critério justificativo de sua valorização. Daí decorre a importância da precisão do significado de cultura, termo acoplado à ideia de paisagem que pode simbolizar a possibilidade, por sua depuração, de medidas efetivas e imediatas de políticas de preservação. Por isso, esse artigo pretende centrar o foco na construção histórica de seus significados. Recuperando seus diversos sentidos e interpretações, pode-se ampliar um debate no sentido de permitir a formação de uma política patrimonial efetiva, que mereça realmente o investimento da sociedade, tanto em termos econômicos quanto em valor patrimonial. Faz-se mister precisar a irreversível seletividade do legado histórico que a sociedade do presente tem a responsabilidade de transmitir à futuras gerações.

\section{Paisagem cultural: a evolução da ideia de preservação integrada homem-natureza}

Apesar de aparecer recentemente em destaque, o interesse pela preservação da paisagem não teve início na Convenção do Patrimônio Mundial de 1992, quando se definem as paisagens culturais, mas advém do pós-guerra. Já existiam mecanismos de preservação nesse sentido, elaborados na $12^{\mathrm{a}}$ sessão da Conferência Geral da Unesco de 1962 e, posteriormente na $17^{\mathrm{a}}$ sessão Conferência Geral da Unesco de 1972. Por que, então, a necessidade de qualificar a paisagem como cultural para fins de preservação, 30 anos mais tarde? O que distingue esse conceito dos anteriores? Até então, a paisagem aparecia enquanto materialidade, como objeto central da preservação. Podendo ser natural ou construída, a preocupação visava à "salvaguarda da beleza e da característica das paisagens e dos sítios de preservação e, desde que seja possível, a restituição dos aspectos das paisagens e dos sítios, naturais, rurais ou urbanos, que sejam devidos à natureza ou à obra do homem" (UNESCO, 1962, p.141). A preocupação com a restituição dos lugares deve-se, certamente, aos prejuízos efetuados pelas guerras mundiais.

Dez anos mais tarde, as paisagens estariam compreendidas como parte dos "locais de interesse", já que não aparecem claramente explicitadas em 1972. Na 17 sessão da Conferência Geral da Unesco, são classificados os monumentos, os conjuntos e os locais de interesse. Diferentemente da separação anterior, agora, seriam alvo de proteção também, além das 'obras dos homens", as "obras conjugadas do homem e da natureza, e as zonas, incluindo os locais de interesse arqueológico, com um valor universal excepcional do ponto de vista histórico, estético, etnológico ou antropológico" (UNESCO, 1972, p.3). Apesar da preocupação da preservação de conjuntos históricos ou tradicionais ampliar a escala da preservação na Carta de Nairóbi de 1976 (UNESCO, 1976, p. 22), o termo paisagem só seria retomado explicitamente em 1992, por ocasião 
na $16^{\mathrm{a}}$ sessão da Convenção do Patrimônio Mundial e recupera, em seu artigo $1^{\circ}$, o debate estabelecido a partir de 1972, referindo-se diretamente às "obras conjugadas da natureza e do homem". Pela amplitude de significados que pode adquirir a relação entre o homem e a natureza, fez-se necessário precisar um pouco mais os termos em que se colocava essa questão, sob risco de se ter um instrumento ineficaz em termos preservacionistas. A Unesco explicita, então, posteriormente, que as "paisagens culturais refletem frequentemente técnicas especificas de utilização viável das terras, considerando as características e os limites do ambiente natural na qual se estabelecem e uma relação espiritual específica com a natureza" (UNESCO, 2013). (grifo nosso) Restringindo desta forma a definição do conceito de paisagem cultural, só estariam incluídas, praticamente, as áreas rurais que utilizam "técnicas específicas de utilização viável das terras". Assinala, ainda, que a proteção pode se referir a técnicas modernas ou tradicionais, que sejam úteis à diversidade biológica, o que estende o debate a questões da atualidade, sem por isso precisar o foco da preservação. Aqui terminam as definições colocadas na Resolução de 1992. Alguma informação suplementar seria possível quando exemplos são citados, inserindo, também, “os jardins, os lugares sagrados, etc.”, que, junto com os terraços, "testemunham o gênio criador do ser humano, da evolução social, do dinamismo espiritual e do imaginário humano" (UNESCO, 2013). Restrita aos jardins e às culturas rurais, como se explicaria a inclusão do Rio de Janeiro como paisagem cultural, único exemplar brasileiro na lista do Patrimônio Mundial da Unesco?

Visando estabelecer parâmetros de preservação, a paisagem cultural será detalhada, pela Unesco, em três categorias: 1. Paisagem intencionalmente criada pelo homem, "o que compreende jardins e parques, criados por razões estéticas", associados (na maior parte dos casos), ou não, a conjuntos religiosos; 2. Paisagem evolutiva, que resulta de uma exigência, em sua origem, "social, econômica, administrativa e/ou religiosa, e atinge sua forma atual por associação e em resposta ao ambiente natural”. Divide-se em duas categorias: paisagem relíquia ou viva, segundo a permanência, ou não, de formas tradicionais ainda ativas na sociedade contemporânea; 3. Paisagem cultural associativa, pela "força de associação dos fenômenos religiosos, artísticos e culturais do elemento natural mais do que traços culturais tangíveis que podem ser insignificantes ou mesmo inexistentes" (UNESCO, 2009, p. 7 e 8).

Em nenhuma das categorias percebe-se, claramente, uma intencionalidade de ir além da restrição de parques e jardins ( $1^{\text {a }}$ categoria $)$, meio rural ou formas tradicionais ( $3^{\mathrm{a}}$ categoria); estas últimas podendo, ou não, permanecer ainda ativas. A segunda categoria prescinde de precisão, já que tudo que existe teve uma origem "social, econômica, administrativa e/ou religiosa, e atinge sua forma atual por associação e em resposta ao ambiente natural". O fato de estar, ou não, ativa em nada esclarece a característica paisagística. Somente o fato de se constituir como "modo tradicional de vida" poderia assinalar um conteúdo específico à paisagem cultural (UNESCO, 2009, p.8).

As práticas brasileiras em termos de preservação da paisagem cultural, no entanto, não se atêm à relação que os grupos tradicionais estabelecem com o ambiente. $\mathrm{O}$ debate dos termos a serem preservados flutuam sem definições muito precisas. 
Considerando-se a paisagem como "um conjunto heterogêneo de formas naturais e artificiais" (SANTOS, 1988, p. 69), percebe-se, atualmente, que a dualidade estabelecida historicamente entre esses dois aspectos, não se apresenta mais de maneira tão clara. Pode-se considerar, no momento presente, a dificuldade de se perceber áreas "naturais" que ainda não sofreram algum tipo de modificação, direta ou indireta, resultado de ações humanas. Existe assim uma 'natureza segunda', artificializada, resultado da intervenção social, direta ou indireta, sobre o planeta (SANTOS, 1982; 1992; LEFÈBVRE, 1974). Apesar dessa ressalva, existem elementos naturais (considerando essa natureza já transformada) e objetos criados pelo homem, artificiais, adicionados a essa realidade primeira. Desta forma, a paisagem, compreendida em seu sentido amplo, daria margem à inclusão de tudo "aquilo que se apresenta aos nossos olhos" (FR, 1694), independentemente do ponto de vista do observador ou de seu recurso técnico, tendo em vista que as formas são sempre resultado da interação homem-natureza.

Se a amplitude do debate se enriquece em termos de alargamento dos problemas a serem enfrentados na relação homem-natureza, como política patrimonial faz-se necessário um refinamento nos critérios dos bens a serem selecionados, já que não há qualquer pertinência na indistinção total e, pior ainda, a limitação dos recursos, sempre presente, poderia significar a exclusão de setores importantes que precisariam ser preservados.

Um dos caminhos para se desvendar a questão talvez esteja nas múltiplas significações que o termo 'cultura' vem assumindo, e que não se explicitam claramente quando se trata de preservação patrimonial no Brasil, pelo menos em nível acadêmico ou popular. Por isso, propõe-se aqui um percurso histórico sobre o tema. Se alguns dos seus sentidos são importantes em termos patrimoniais, o que deve abranger diferentes áreas consideradas de valor cultural (material e imaterial), quando se trata de assumir o papel de complemento qualificativo da paisagem não necessariamente devem ser utilizados os mesmos parâmetros. Em todo o caso, ainda é uma discussão em aberto. Para pensar o problema, conjuntamente, propõe-se como primeiro passo, um breve percurso sobre as trajetórias históricas da cultura.

Não se pretende aqui detectar a origem do temo 'cultura', somente percorrer uma trajetória que marca os seus significados herdados. O recuo no tempo fezse necessário devido às descontinuidades e recuperações de significações, que não acompanham necessariamente um movimento contínuo ou linear. Os sentidos se entrecruzam; reconstitui-se uma acepção em determinado momento, buscada de um período mais distante e não necessariamente em um tempo imediatamente precedente. As reconstruções são complexas. Procura-se identidades, mas também adaptações às novas realidades. Quais significados de cultura poderiam, hoje, colaborar com as diversas políticas patrimoniais? Selecionou-se, então, algumas das interpretações que poderiam favorecer o presente debate, mas procurou-se, também, mostrar algumas evoluções e desdobramentos do termo desde seu aparecimento. 


\section{A cultura do homem e do campo}

Pouco se encontra na Antiguidade referente à cultura, que não seja relacionado ao cultivo das terras. Virgílio enaltece os campos em seus poemas As Geórgicas, elaborados entre 36 a 29 a.C.: "sobre estas encostas risonhas o cacho escurecerá / Aqui são os pomares que enriquecem a cultura"; e avisa sobre os perigos que advêm da falta de trato com a terra: "Que um vale ceifado dorme um ano sem cultura / Seu seio reconhecido paga com usura" (VIRGILE, 1819, p. 4 e 5). Virgílio alerta ainda para os horrores que tornam "as cidades sem lei, a terra sem cultura", como se ambas fossem a antítese dos ideais almejados. "Terra sem cultura" seria a contraposição de sua realização (VIRGILE, 1819, p. 17). A necessidade de cultivar, como atividade humana de cuidar da terra está presente em Virgílio em diversas passagens, afirmando que "todas as árvores enfim têm necessidade de cultura", pois é esta que torna um solo mais promissor e pode, assim, colmatar os desejos (VIRGILE, 1819, p. 19). A cultura aparece, assim, como resultado positivo da ação humana.

Reconhece-se Cícero como o responsável pela transformação do significado de cultura, que seria transportado para o campo do desenvolvimento pessoal, a partir do estabelecimento da correlação entre o plantio da terra, o ato de cultivar, agora relacionado ao espírito humano. Uma "alma bem nascida" seria comparável a uma boa terra, "com sua bondade natural, uma e outra têm ainda necessidade de cultura, se pretendemos que deem frutos. Ora, a cultura da alma é a filosofia" (CICÉRON, 1841, p.13). Aqui, o ato de cultivar como processo de elaboração adquire uma importância primordial para o enriquecimento humano. Mesmo uma "alma bem nascida, tal como uma boa terra, com sua bondade natural, uma e outra ainda teriam necessidade de cultura" (CICÉRON, 1841, p.13). A cultura poderia sempre trazer um acréscimo em relação às dotações naturais, mesmo nas melhores condições oferecidas.

A versão romana da origem do sentido da cultura humana, seria, no entanto, oriunda de Filão de Alexandria que escreve De Agricultura em 37 a.C., interpretando a prática de Noé, na Gênese, como "cultura da alma" e colocando a filosofia a serviço da "formação moral" (Novara, 1986, p. 54). Filão teria se nutrido dos trabalhos de Platão, de Fedro (escrito por volta de 370 a.C.) e da República, onde, em seu Livro IX, referese ao "homem interior", que exerceria a maior autoridade possível sobre o "homem inteiro", como um lavrador que nutre as espécies pacíficas e impede os selvagens de crescer; dividindo seus cuidados entre todos, poderia "mantê-los em inteligência entre eles e consigo mesmo" (PLATON, 1949, p. 134; PLATON, 1834, p. 687). O que se lê em Timeu sobre o homem como uma "planta celeste", também estaria presente em Filão (NOVARA, 1986, p. 54). No entanto, o autor de "cultura animi" não se referenciou nas fontes gregas, porque não lhe foram acessíveis. Cícero polemizava com o estoicismo, substituindo homus cultus, definição vaga e imprecisa, por cultura, como colaboradora da natureza. A auto-cultura estaria inscrita na própria natureza do homem, o que faz sugerir "uma interação entre o crescimento da vinha" e a "progressão, o progresso da "cultura" (NOVARA, 1986, p. 58). O termo cultura iria, no entanto, se empobrecer sob o Império. A alma romana perdendo seu fôlego, seriam os autores cristãos que the 
retomariam no século V, com Enódio, adotando múltiplos significados (NOVARA, 1986, p. 66). Cultura se acompanha de 'culto', que significa homenagem à divindade, mas é prioritariamente entendida como parcela de terra.

O termo 'cultura', constatado já no século XII, dispersa-se através da canção de gesta "Le Pelèrinage de Charlemagne", escrita em versos alexandrinos em 1150, como colture, terra cultivada. (CNRTL, 2012) No latim antigo, cultura significa um pedaço de terra cultivada. (LITTRÉ, 1874) O sentido do termo se mantém, relacionado à produção agrícola, como nos escritos de direito de Philippe de Beaumanoir (1900), nas obras de poesia de Rutebeuf e de Roman de Renart, efetuados no decorrer do século XIII (LITTRÉ, 1874). A acepção de "terra cultivada está presente também em Énéide, tradução da obra de Virgílio em 1509 [ed. 1540], feita por Octavien de Sainct-Gelays, poeta e tradutor francês (CNRTL,2012). A cultura é vista como as maneiras que se utiliza para tornar a terra mais fértil, para fazer crescer mais facilmente as árvores e as plantas para que tragam melhores resultados, como nas vinhas (FR, 1694, Tomo 1, p. 298). Trata-se de exercitar o trabalho com foice na terra, árvores e plantas para que possam trazer frutas e flores. Considera-se uma "arte de cultivar a terra para que produza frutos" (RICHELET, 1732,p.455). Cult ter-se-ia derivado do verbo -cole, que daria origem a cultivável, cultivar, cultura, agricultura, arboricultura, floricultura, horticultura, viticultura, culturismo, aculturação (De CLERQ, 2000, p. 57). Aparece também na forma -cole colo, -ere, colui, cultum : como cultivar; cuidar, como se procede na avicultura, viticultura, ou apicultura (De CLERQ, 2000, p. 57).

No século XVI, ao lado da atividade de produção nas terras rurais, destaca-se a 'cultura da língua', ou seja, o enfoque se estabelece em um processo, uma ação (CNRTL, 2012; Littré, 1874). Em duas passagens de Bellay (1549) aparecem referências à cultura da língua: 1. Se os antigos Romanos tivessem sido tão negligentes com a cultura de sua língua (p.65); 2. [..] se os gregos e os romanos, mais negligentes à cultura de suas línguas ... (p.66). A força do novo significado se impõe, quando 'cultivar' e 'cultivado' passam a adquirir mais destaque do que a própria questão da 'cultura' como produção rural. Cultivar, como no latim excolere, significa "compreensão cultivada de doutrina", tendo como seu antônimo, "o que não é cultivado, inculto" (ESTIENNE, 1539, p. 127; RANCONNET, 1606, p. 171). Nota-se, portanto, uma agregação de sentido que se origina de um ato voluntário, que se prolonga pelo século XVII, como a "cultura das boas letras" ou refere-se aos seus resultados na "formação do espírito pela educação" (CRNTL, 2012). Pode-se considerar que, apesar de se estender o sentido do termo cultura à língua e ao espírito, adquirindo, portanto, um sentido de aperfeiçoamento, até aqui são estabelecidos somente os primeiros passos no sentido da ampliação do seu conteúdo em termos civilizatórios, o que adviria com as grandes transformações sociais do século das Luzes.

\section{A cobiça pela grande cultura na era iluminista}

A partir do século XVIII explicita-se o termo cultura como tendo adquirido, também, um "sentido figurado", do cuidado que se empreende nas artes e no espírito 
(FR, 1762; 1798; 1832-5; 1932-5; 1992). Significa, também, a necessidade de empenho para que se possa atingir algum aperfeiçoamento pessoal: "trabalhar a cultura do espírito" (FR, 1762). Cultivar passa a dar ênfase ao processo de aperfeiçoamento, ao esforço e seus resultados: "O pouco de conhecimento que tenho, devo à cultura das boas letras"; ao "exercício que se faz para aperfeiçoar e polir as ciências ou o espírito". O crescimento pessoal passa a se relacionar com a aquisição de conhecimento. Dever-se-ia, então, "pensar à cultura das artes e das ciências, trabalhar para a cultura do espírito". O objetivo deste processo de aperfeiçoamento contínuo estava claramente definido, já que o homem deveria "se esforçar para chegar à perfeição" (RICHELET, 1732, p.455).

A Enciclopédia de Diderot e D'Alambert, além de desenvolver um esmiuçado estudo sobre a cultura das terras e o ato de cultivar, inclui o termo 'culto' como uma homenagem a Deus, "porque é nosso mestre soberano", mas aqui refere-se à alma humana, como "culto interior". Sem tratar diretamente o tema "cultura', descreve os procedimentos do cultivar, onde seriam essenciais o labor, a irrigação e a conduta. A agricultura é concebida como a arte de melhorar a terra por meio de trabalho (DIDEROT; D'ALEMBERT, 1765, p. 550-566). Essa ideia de progresso se transporta do esforço agrícola para a acumulação de um saber que aperfeiçoa o espírito humano.

Apesar de um começo tímido em termos de amplitude humanista do sentido cultural, Voltaire ou Rousseau expressam, em suas obras, a concepção de seu tempo, importando, aqui, a ambição ao homem esclarecido. Voltaire, em Les Lois de Minos (obra de 1749), define a sociedade em que vive, prioritariamente, como conflituosa e agrícola: "A cultura dos campos, a guerra são nossas artes" (VOLTAIRE, 2008, p.15). O cultivo dos campos se faz presente em muitas passagens de sua obra, mas a 'cultura' enquanto aquisição social ganha destaque como elemento fundamental do aperfeiçoamento humano. Em Les Guèbres, ou la tolérance, observa que « a cultura das artes torna sempre as almas mais honestas e puras" (VOLTAIRE, 1877, p. 490). Salienta, assim, a possibilidade de aperfeiçoamento pessoal, através da aquisição contínua do conhecimento. Assim, as ciências e as artes precisariam ser cultivadas. Em suas Cartas Filosóficas, Voltaire exalta as sociedades que assim procedem ou procederam: "Houve um tempo na França onde as Belas Artes eram cultivadas pelos primeiros do Estado" (VOLTAIRE, 1734, p. 38). Reporta-se, também, à necessidade de desenvolvimento da ciência: "pouco tempo depois, a física experimental começou a ser cultivada ao mesmo tempo em quase todas as partes da Europa" (VOLTAIRE, 1734, p. 18).

Ser cultivado deriva, portanto, de um processo de elaboração. Os verdadeiros sábios seriam sempre em pequeno número, "pois para usar a ciência, seria necessário reunir grandes talentos e grandes virtudes", o que só se pode esperar de "algumas almas privilegiadas" (ROUSSEAU, 1750, p. 38). Cultura implica na elevação das qualidades humanas e do comportamento social, "a cultura das letras engendra insensivelmente a polidez", "o gosto nasce da mesma fonte" (ROUSSEAU, 1750, p. 54). Rousseau não poderia imaginar que espectadores de Molière - aos quais ele admirava a delicadeza -, pudessem ser capazes de uma expressão grosseira, porque tudo poderia ferir "as suas castas orelhas" (ROUSSEAU, 1750, p. 38). A cultura transforma-se, então, em 
refinamento; na capacidade de admirar e reconhecer que a eloquência de Cícero era mais importante do que "seu zelo", que ele, Rousseau, preferiria compor as Catilinárias do que salvar seu país. "Eis o efeito sempre seguro da cultura das letras", o desenvolvimento da faculdade de "educar e de enobrecer a alma" (ROUSSEAU, 1750, p. 61).

A cultura se transmite e, assim, permite o aprimoramento da humanidade, ideia essa muito cara à ação patrimonial. Aparece, assim, como um processo pessoal, mas também social. O homem torna-se capaz de realizar acréscimos no sentido do aperfeiçoamento da própria natureza, que se transmite de forma cumulativa: "Ele recebe de minha mão os frutos de minha cultura/Doces presentes com os quais minha arte embeleza a natureza" (VOLTAIRE, 1877, p. 544). O homem interfere na natureza em um sentido sempre positivo, em sua própria elaboração.

A educação torna-se o caminho indispensável para a acumulação de saber, no sentido de tornar o homem mais ilustrado, culturalmente mais enriquecido. Voltaire eleva a cultura ao valor supremo. Referindo-se aos grandes poetas e escritores ingleses, reconhece-lhes o mérito de terem cultivado "as letras como se fossem atingir a sua fortuna", mas também, a capacidade de influenciar aqueles que precisariam ser conduzidos neste mesmo caminho. Para ele, esses escritores tornaram "as artes respeitáveis aos olhos do povo, que tem necessidade de ser conduzido pelos grandes e que, entretanto se inspira menos neles na Inglaterra do que em qualquer outro lugar do mundo" (VOLTAIRE, 1734, p. 40).

Os escritores desempenham um papel importante na expansão cultural, porque necessitam, também, da aprovação pública. Refletindo sobre as maneiras de agradar seus leitores, eles acabam por desenvolver um estilo e, assim, promovem a depuração do gosto e espargem graça e urbanidade em todos os lugares (ROUSSEAU, 1750, p. 54). Tratava-se, portanto, de um projeto civilizatório.

A sociedade deveria se pautar na razão e, assim, haveria que cultivar o saber. Ser cultivado deriva de um processo contínuo que requer esforço e trabalho, mas que depende de um ambiente social favorável. Uma sociedade letrada é vista como um avanço e uma benesse: "sua grande felicidade foi não somente ter nascido num país livre, mas em um tempo onde as impertinências escolásticas tinham sido banidas, somente a razão era cultivada; e o mundo somente poderia ser seu mestre, e não seu inimigo." (VOLTAIRE, 1734, p. 24).

Cultura aprimora-se no decorrer do século XVIII, sendo considerada como sentido figurado da atividade agrícola, como a possibilidade de melhoria nos costumes, nas artes e nas ciências, que necessitam de processos de desenvolvimento. Recomendase, assim, "trabalhar a cultura do espírito", sendo que "a cultura das ciências forma o espírito" (TRÉVOUX, 1771, p.60). Existe, portanto, uma relação direta entre conhecimento e aperfeiçoamento da humanidade. 


\section{Kultur e a valorização das diferenças}

Somente na segunda metade do século XVIII a palavra Kultur torna-se usual na Alemanha, talvez com uma utilização vinda diretamente da influência francesa, no sentido de civilização. Pela ausência de dicionários históricos na Alemanha, não se pode detectar o aparecimento da palavra Kultur antes dessa época. Nas fontes de referência francesas, cultura aparece acompanhada de algum complemento: "cultura do trigo" ou 'cultura das artes", por exemplo (LITTRÉ, 1874; FR, 1798). Os escritores Vauvenarques e Voltaire teriam sido os primeiros a empregá-la em termos absolutos, atribuindo-lhe o sentido de "formação de espírito" (TONNELAT, 1930, p. 65).

$\mathrm{Na}$ Alemanha, o termo Kultur apresenta diversos significados. Designaria liberdade de espírito frente aos preconceitos; distinção e fineza nas maneiras, mas também estado social, opondo-se à barbárie dos povos selvagens (TONNELAT, 1930, p. 66). Essas concepções estão presentes nos grandes escritores da época. Herder identificava vários estágios de desenvolvimento da humanidade. Opunha as 'nações cultivadas', mas reconhecia que até os povos mais grosseiros teriam ainda algum conhecimento, desde que tivessem "atingido uma lei moral; até aqui suas capacidades, por maior que fossem, ainda não teriam que ser despertadas" (HERDER, 1827, Tomo 1, p. 31). Comparava os estágios da humanidade às fases da vida, desde a infância, juventude, maturidade e velhice sem com isso pretender esgotar a filosofia da historia da humanidade. Diferentes povos poderiam apresentar o mesmo grau de cultura. Para Herder, cultura poderia significar cultivo, ação de cultivar o solo, o que dependeria do "nobre esforço do homem" (HERDER, 1827, Tomo 2, p. 54). A sociedade caminharia, por estágios, sempre em direção ao melhor. Somente após ter suplantado sua primeira fase de domesticação dos animais, pôde desenvolver o comércio, as ciências e as artes. O uso habitual da língua constituiria a terceira etapa do termo Kultur. Reconhecia, portanto, a acumulação e a produção sociais no aperfeiçoamento humano, que muito devia ao desenvolvimento da linguagem e da escrita: "Se a linguagem é o meio de desenvolver os homens como homens, a escrita é o meio de formar uma educação científica." (HERDER, 1827, Tomo 2, p. 172). Os povos que não tiveram essa "tradição artificial" ficaram, então, sem cultura. Refere-se, também, a uma qualidade do homem 'esclarecido', emprestando esta expressão ao Iluminismo (HERDER, 1827, Tomo 2, p. 147). Trata-se, aqui, portanto, de adquirir certa erudição, capaz de permitir os avanços científicos.

Não se trata, no entanto do único sentido atribuído à cultura, já que Herder considera que a habilidade na utilização dos instrumentos também qualifica a humanidade. O progresso material teria importância tanto quanto a evolução das ciências abstratas. Observa, então, que o 'selvagem' que pensa por si mesmo e se exprime com precisão e energia, "aquele que na esfera de sua atividade sabe exercer com presença de espirito suas faculdades morais e físicas, sua inteligência e alguns instrumentos mais ou menos perfeitos", teria uma cultura mais real do que o politico ou o sábio, pois esta teria sido desenvolvida por outras mãos ou mesmo por outras gerações anteriores (HERDER, 1827, Tomo 2, p. 180). Valoriza, portanto, a cultura do homem comum, considerada original. 
Haveria, portanto, uma diferenciação entre o estágio de desenvolvimento das populações, o que poderia acarretar desigualdade no contato entre os povos. Na relação entre nações ocorreria, portanto, o perigo de subjugo, semelhante àquele que se apresenta quando um chefe se destaca de seu povo e age por si mesmo. No entanto, colocada dentro de seus limites, reconhece o papel civilizatório da cultura na relação entre nações. Enquanto uns “deram às nações suas culturas; não tiveram outro objetivo que civilizá-las” (HERDER, 1827, Tomo 2, p.190). A desigualdade entre povos nos estágios de desenvolvimento provocaria, então, uma transmissão civilizatória, tendo o termo "cultura" adquirido aqui esse caráter, provavelmente também herdado do Iluminismo francês.

Herder questiona os usos das descobertas que, se por um lado, permitiriam poupar esforço humano, por outro, multiplicariam as necessidades, o que não levaria obrigatoriamente à felicidade. Os gênios criadores promovem tanto resultados perigosos quanto benéficos. Foram os responsáveis pelas grandes invenções, sem poderem determinar o uso dessas descobertas, nem decidir se seriam, ou não, para todos (HERDER, 1827, Tomo 2, p. 184-185). A sociedade, no entanto, caminha sempre para melhor, apoiada nos esforços e nas sucessivas conquistas, efetuados pela razão humana. Os avanços particulares realizados pelos diferentes povos contribuiriam, assim, para o progresso geral da humanidade.

As ideias de Kant assemelham-se em muitos aspectos ao pensamento de Herder, sobretudo no sentido progressivo em direção ao aperfeiçoamento humano, a partir do desenvolvimento da razão. A natureza teria sido bem estrita, atribuindo o mínimo e o mais justo ao homem. Teria agido com parcimônia, dotando-o somente para as necessidades essenciais de uma existência inicial; "como se houvesse querido que o homem, quando tivesse alçado da maior incultura à maior habilidade, à perfeição interior no modo de pensar" pudesse, então, atingir a felicidade, por mérito próprio (KANT, 2002, p. 8). O homem poderia negligenciar seus dons naturais, mas lhe foi atribuído um talento, que "graças a alguma cultura" poderia fazer dele um homem útil em muitos aspectos (KANT, 193, p. 25). Haveria uma escalada da existência singela à cultura, "cultura que se baseia no valor intrínseco do homem, ou seja, seu valor social” (KANT, 2002, p. 9). Esta seria a escalada destinada à humanidade.

Para Herder, assim como para Schiller, cultura refere-se a um movimento contínuo de crescimento da humanidade, como um bem comum (TONNELAT, 1930). Somente com Goethe, vem designar os traços distintivos de um povo determinado, ideia aprofundada, sobretudo, a partir de sua viagem à Itália. Seu pensamento parte também da analogia entre a produção na terra e a elaboração humana. Como acontece nas terras agrícolas, homens podem ser incultos, desigualmente ou cuidadosamente cultivados, ou mesmo existem "pessoas de uma cultura média." (GOETHE, 1862, p. 188). Há graus na cultura humana tanto quanto nos campos mais ou menos cultivados, sem que sejam inertes, podendo-se afluir de um estado a outro. Existe, portanto, a possibilidade de crescimento pessoal, o que ocorre a todos os homens, mesmo aos mais ilustrados. Goethe considera que sua viagem à Itália seria uma dessas oportunidades de "se instruir 
e se cultivar" (GOETHE, 1862, p. 186). A viagem faria parte, também, desse processo contínuo de aperfeiçoamento interior, pois “os espíritos progressivos não se contentam com o deleite, "eles querem conhecer" (GOETHE, 1862, p. 419). Tudo, portanto, deveria ser cultivado, mesmo "sua barba inculta" que se acrescentava "ao ar selvagem" de sua pessoa, ou a voz de uma pessoa, para que pudesse se aprimorar (GOETHE, 1889, p. 114). O enriquecimento pessoal traria benefícios ampliados, pela possibilidade de sua propagação através do convívio social. Dever-se-ia, portanto, "procurar os homens cultivados, os homens que aspiram à cultura" (GOETHE, 1863, p. 441). Trata-se de se procurar o aprofundamento, se ir "a fundo", de "amadurecer os conhecimentos nas artes" (Goethe, 1862, p. 369). Deve-se nutrir, portanto, a cultura interior, o que provoca a distinção entre os indivíduos. "Que diferença entre o homem que quer tirar de dentro sua cultura, e aquele que quer agir no mundo e lhe dar uma instrução comum!” (GOETHE, 1862, p. p. 255).

Goethe reconhece a importância de suas viagens, que lhe oferecem a possibilidade, também, de uma nova visão de mundo. Além do prazer, destaca o impacto sobre sua capacidade de percepção da realidade que o circunda: "Para mim, ao menos, parece que nunca apreciei com tanta justeza as coisas deste mundo. Eu me animo com as consequências positivas que resultarão para toda a minha vida" (GOETHE, [1786], 1862, p. 186). É sobretudo a formação do homem interior, Bildung, que constitui a preocupação de Goethe, mas em sua viagem, ele discerne mais claramente que existe o indivíduo e seu meio, com o qual partilha hábitos comuns, gostos e formas de pensar, aqui se constitui propriamente Kultur.

Goethe coloca cultura no plural, distinguindo as sociedades por características específicas. As culturas seriam possíveis pela particularização dos traços específicos. Encontrou em "Pompéia uma boa e alegre sociedade napolitana" (GOETHE, 1862, p. 254). Os dois sentidos, como erudição e como característica das populações, se confundem em alguns momentos. A Itália aparece como uma nação de homens cultos, pois, para ele, "sempre se considerou a Itália como uma nova Jerusalém de pessoas verdadeiramente cultivadas" (GOETHE, 1862, p. 429). "Era uma sociedade cultivada", afirma Goethe, para distinguir grupos sociais e nações (GOETHE, 1862, p. 254). Goethe destaca, assim, que uma sociedade de pessoas "de cultura iminente se reunia em sua casa às sextas-feiras" (GOETHE, 1863, p. 232). Para isso, era preciso estar à altura de seu meio, já que "um homem como ele deveria produzir a mais doce impressão num círculo intimo de pessoas cultivadas" (GOETHE, 1863, p. 305).

As sociedades impregnam e permitem a apropriação da cultura nacional, noção que incarna a distinção de traços culturais. O homem "quando penetrado do espírito nacional, se sente, pelo efeito de um gênio que o habita, capaz de interagir com o passado e com o presente"; quando ele encontra sua nação "num alto grau de civilização, isso torna mais fácil sua própria cultura” (GOETHE, 1863, p. 452). O meio em que nasce permite a incorporação de uma cultura acumulada, estimulando mais facilmente um aperfeiçoamento intelectual ou certa erudição. Em Goethe não somente existe a 
explicitação da diferença das características sociais, como também a constituição dos meios culturais, devido às produções acumuladas e às heranças transmitidas.

Não se trata mais somente de um crescimento cultural pessoal ou social indistinto ou universal. Agora, mesmo as características pessoais deixam transparecer os traços culturais, como em Madame de Staël, que "representa a cultura francesa na sua pureza" (GOETHE, 1863, p. 258). A cultura nacional constitui-se em via de mão dupla . A cultura de uma nação aparece, também, como legado histórico passado ou presente, na perspectiva futura. Existe o "desejo de se apropriar da cultura alemã", como também "de consagrar seus novos talentos à cultura e ao bem de sua pátria" (GOETHE, 1863, p. 331). A noção de herança e acumulação histórica está portanto claramente colocada.

A particularização das culturas em Goethe não significa a falta de reconhecimento da contribuição das nações ou regiões para o patrimônio mundial. Segundo ele, durante um longo e feliz período de paz, a cultura estética e literária se desenvolveu na Alemanha, mas "essa cultura que se dirigia somente ao homem interior", desenvolve nele uma certa "sentimentalidade, onde "não se pode deixar de reconhecer sua influência", nem em sua origem e nem seu desenvolvimento (GOETHE, 1889, p. 180). As grandes obras desempenhariam um papel especial na possibilidade do homem se instruir e se cultivar (GOETHE, 1862, p. 186). Goethe considerava que fazia parte de sua "natureza venerar com prazer, alegria, o grande e o belo" e que "cultivar dia após dia, hora por hora, esta disposição na presença de objetos magníficos, é o sentimento mais delicioso que se pode experimentar" (GOETHE, 1862, p. 106).

A cultura é portanto, também, herança de grandes obras, de homens ilustres, do passado, considerando que "os antigos representam a existência e nós o ordinário, o efeito; eles descrevem o horrível, e nós, horrivelmente; o agradável, e nós, agradavelmente" (GOETHE, 1862, p. 362). Na Itália sentiria a presença do "solo clássico", "essa convicção produzida no espirito pelos sentidos de que aqui esteve antes a grandeza, que ainda está e que ela estará". Lamenta a deterioração das grandes obras, pois "não devíamos passar tristemente por monumentos destruídos: ao contrário, devíamos celebrar poder ver tantas coisas conservadas" (GOETHE, 1862, p. 443).

Com Goethe, importantes passos são dados nas contribuições particularizadas dos diferentes grupos culturais, mas também na necessidade de acumulação e transmissão dos saberes e dos objetos concebidos pela humanidade. O iluminismo, certamente, significou uma amplitude no conceito de cultura enquanto movimento civilizatório da humanidade e do homem, mas que necessitaria de acumulações e das particularidades para compor uma totalidade de grande valor histórico.

\section{Cultura e proteção patrimonial}

O iluminismo e a virada do século colocam a valorização dos objetos e das práticas dos grupos, preparando os atos efetivos e sistemáticos em termos de proteção patrimonial. Se a antiguidade conhecia as escavações por motivos científicos ou religiosos, as heranças são concebidas na Idade Média de acordo com os interesses da Igreja e da 
Monarquia hereditária, dando destaque às relíquias et regalia (objetos utilizados para sagração dos reis) (LENIAUD, 2015). Ter-se-ia que esperar o século XIX para, por um lado, se efetuar uma política mais sistemática de preservação do patrimônio material, mas também para o surgimento de uma disciplina cujo objeto de estudo estivesse centrado sobre grupos humanos e sua diferenciação. A cultura transforma-se em objeto de estudo de uma nova ciência, a antropologia. Teria sido definida primeiramente por TYLOR, em 1871, como um todo complexo que inclui conhecimento, crença, arte, moral, costumes, e outras capacidades de hábitos (TYLOR, 1871). De lá para cá, a definição de cultura nada mais faz do que se ampliar. Originária do estudo das sociedades primitivas, abrange as sociedades tradicionais, mesmo aquelas que permanecem no mundo atual, e o estudo da vida contemporânea na cidade ou na empresa se constituem em novos eixos de pesquisa (COPET-ROUGIER; GHASARIAN, 2015) .

A Unesco se propõe a valorizar o sentido amplo de cultura para fins societários, engloba "as artes e as letras, os modos de vida, os direitos fundamentais do ser humano, os sistemas de valores, as tradições e as crenças". Defende as sociedades e os grupos que considera em 'perigo' de perda de identidades e especificidades. A cultura "no seu sentido mais amplo, é considerada como conjunto de traços distintivos, espirituais e materiais, intelectuais e afetivos, que caracterizam uma sociedade ou um grupo social" (UNESCO, 1982). Desenha, assim, a possibilidade de um projeto de sociedade, do qual fazem parte grupos heterogêneos, quando define o reconhecimento de amplos valores sociais e culturais. Recupera, portanto, o sentido de Kultur, quando coloca em destaque as especificidades dos lugares. Estas, por sua vez, dependem das práticas particulares dos grupos sociais sobre o ambiente, como um todo complexo que inclui conhecimento, crença, arte, moral, costumes, e outras capacidades de hábitos (TYLOR, 1871).

Concentrados na preocupação quanto às heranças culturais, os organismos internacionais ligados ao patrimônio, além de se preocuparem a conceituação de cultura, estabeleceram políticas de preservação, durante longo período, nesses dois campos distintos : os objetos materiais (em diversas escalas, esculturas, arquiteturas, paisagens, etc.) e os grupos sociais, com suas ações e representações. Mesmo se servindo dos bens materiais para a análise dos grupos (os utensílios, por exemplo) o foco da análise antropológica são as práticas, valores, modos de vida. A paisagem cultural aparece como possibilidade de romper essa divisão estabelecida, num mundo cuja lógica do processo de acumulação coloca em primeiro plano as questões ambientais.

O Brasil deveria dedicar maior atenção tanto no caráter amplo do conceito quanto incorporá-lo ao debate sobre a construção de um projeto de sociedade. Para isso, as diversas acepções de cultura, construídas historicamente, colocam grandes possibilidades que vão bem além do recorrente discurso restritivo ao campo econômico que se faz presente de modo quase exclusivo nos assuntos de Estado. Para além dos especialistas, o acesso à cultura precisa de um lento processo de elaboração, o que vem a significar, claramente, uma opção em termos de projeto social.

Por outro lado, o debate sobre as paisagens culturais no Brasil ainda se configura de maneira inicial. Além da defasagem da aprovação da chancela em relação aos 
procedimentos internacionais, o Brasil vacila no reconhecimento de paisagens culturais que protegem formas tradicionais que ainda estejam ativas atualmente. Os parques e jardins, assim como as paisagens históricas já dispunham de atenção, mesmo que precária, em termos de preservação. Os desafios da paisagem cultural ativa são maiores, já que colide com interesses decorrentes do processo de concentração econômica. No entanto, talvez por isso mesmo, devesse haver o empenho na proteção dessas formas tradicionais, que significam maneiras de produzir condizentes com a proteção da paisagem, num mundo em que já se contestam claramente os efeitos da devastação ambiental sobre a qualidade de vida. Aqui talvez resida a importância maior do resgate do debate cultural. Seria ele capaz de lançar um novo foco sobre as políticas de preservação, colocando em destaque as diferenciações das paisagens singelas, elaboradas por técnicas tradicionais.

A proteção das pequenas e múltiplas formas de interação com a natureza evita, também, processos de pauperização por destituição dessas populações de seu ambiente e de seu saber-fazer. Por outro lado, manifestações culturais significativas estão ligadas ao próprio procedimento de organização da reprodução da vida dos diversos grupos sociais. Da sazonalidade dos plantios, muitas vezes, decorreram as festas, os rituais, as crenças. Os sentidos tradicionais de cultura - agrícola, humana e social - se encontrariam ali harmonizados. A paisagem cultural se reconciliaria, assim, com a relação viva do homem e seu ambiente.

\section{Referências}

BEAUMANOIR, Philippe (1250?-1296). Coutumes de Beauvaisis. Texte critique publié avec une introduction, un glossaire et une table analytique, par Am. Salmon. Tomo 1 e 2. Paris, Alphonse Picard et Fils, 1899 e 1900, 551p.

BELLAY, Joachim de (1549). La défense et l'illustration de la langue française. Paris, Bibliothèque Internationale d'Edition E. Sansot,1905, 236p.

CICERON. Oeuvres Complètes. Collection des Auteurs latins publiés sous la direction de M. Nisard. Tomo 1. Paris, Dubochet, 1841, 554p.

CNRTL (Centre Nationale de Ressources Textuelles et Lexicales). Outils pour un traitement optimisé de la langue (Ortolang), Etymologie. Edição atualizada. CNRS, Université de Nantes, 2012. Disponível em http://www.cnrtl.fr.; acesso : 19 fevereiro 2015.

COPET-ROUGIER, Élisabeth; GHASARIAN, Christian. Anthropologie. Encyclopaedia Universalis. Disponível em www.universalis.fr; acesso: 23 fevereiro 2015.

DE CLERCQ, Danielle. Etymons grecs et latins du vocabulaire scientifique français. Université Catholique de Louvain, 2000, 224p.

DIDÉROT, Denis; d'ALAMBERT, Jean Le Rond. Encyclopédie ou Dictionnaire raisonné des sciences, des arts et des métiers (par une société des gens de lettres). Tomo 3, Neuchatel, Samuel Faulche Imprimeurs, 1765. Disponível: https://fr.wikisource. org/wiki/L'Encyclopédie/1re_édition/Index_tome_3; acesso: 14 fevereiro 2015. 
ESTIENNE, Robert. Dictionnaire Français-latin, contenant les mots \& manières de parler français (françois), tournez en latin. Paris, Robert Estienne, avec privilège du Roi, 1539, 527p.

FR. Le Dictionnaire de 'Académie Françoise dédié au Roy. $1^{\text {a }}$ Edição. Tomo 1 e 2, Paris, 1694, 759p. ; 641p.

FR. Nouveau Dictionnaire de l'Académie françoise dedié au Roy, 2a Edição, (2nd edition), Tomo 2, Paris, 1718, 820p.

FR. Dictionnaire de l'Académie Françoise. $3^{\text {a }}$ Edição, Tomo 1 e 2, Paris, 1740, 884p.; $897 \mathrm{p}$.

FR. Dictionnaire de l'Académie Françoise. 4a Edição, Tomo 1 e 2, Paris, 1762, 991p.; 966p.

FR. Dictionnaire de l'Académie Françoise. 5a Edição, Paris, 1798, 3429p.

FR. Institut de France. Dictionnaire de l'Académie Française, 6a Edição, Tomo 1 e 2, Paris, 1835, 941p.; 973p.

FR. Institut de France. Dictionnaire de l'Académie Française. $7^{\text {a }}$ Edição, Tomo 1 e 2, Paris, 1878, 964p.; 966p.

FR. Institut de France. Dictionnaire de l'Académie Française, 8a Edição Versão eletrônica, colaboração Atilf, Analyse et traitement informatique de la langue française (CNRS - Université de Lorraine) 1932-1935. Disponível em http://atilf.atilf.fr/; acesso 11 outubro 2014.

FR. Dictionnaire de l'Académie Française. 9ª Edição, (CNRS-Atilf), 1992. Disponível em http://atilf.atilf.fr/; acesso 11 outubro 2014.

GOETHE, Johann Wolfgang von (1749-1832). Campagne de France / par Goethe ; trad. française par Jacques Porchat. Paris, Hachette, 1889, 242p.

GOETHE, Johann Wolfgang von. Euvres. Poésies diverses, Pensées. Tradução de Jacques Porchat. Paris, Hachette, 1883, 783p.

GOETHE, Johann Wolfgang von. Mélanges. QEuvres Complètes. Tome X. Traduction nouvelle par Jacques Porchat. Paris, Hachette, 1863, 488p.

GOETHE, Johann Wolfgang von. Voyage en Italie. GEuvres. Tomo IX. Traduction par Jacques Porchat. Paris, Librairie de L. Hachette et Cie, 1862, 504p.

HERDER, Johann Gottfried von (1744-1803). Idées sur la philosophie de l'histoire de l'humanité. Traduzido do alemão e precedido de introdução por Edgar Quinet. Tomo 1 e 2. Paris, Levrault, 1827, 572p; 526p.

KANT, Emmanuel (1784). Idée d'une histoire universelle du point de vue cosmopolitique. Traduction faite à partir de l'édition des oeuvres complètes de Kant de l'Académie de Berlin (Tome VIII). Tradução de Philippe Folliot. Quebec, Edição da Universidade de Chicoutimi, 2002. Disponível em : classiques.uqac.ca ; acesso em 2 janeiro 2015. 
LEFEBVRE, Henri. La production de l'espace. Paris: Éditions Anthropos, 1974, 487p. LENIAUD, Jean-Michel. Patrimoine, art et culture. In : Encyclopaedia Universalis. Disponível em www.universalis.fr.; ; acesso 23 fevereiro 2015.

LITTRÉ, E. Dictionnaire de la langue française. Tomo 1. Paris, Librairie Hachette, 1874. Disponível : www.littre.org; acesso 19 fevereiro 2015.

NOVARA, Antoinette. Cultura: Cicéron et l'origine de la métaphore latine. In: Bulletin de l'Association Guillaume Budé, n 1, mars 1986. pp. 51-66.

PLATON. La République : Livre IX. Oeuvres complètes. Tradução Victor Cousin, Rey et Gravier Libraires, 1834.

PLATON. Phèdre. Oeuvres complètes. Tradução Victor Cousin, Rey et Gravier Libraires, 1849.

RANCONNET, Aimar de (14..-1559). Thresor de la langue francoyse tant ancienne que moderne : auquel... sont les mots propres de marine, vénerie et faulconnerie.... Avec une Grammaire francoyse et latine et le recueil des vieux proverbes de la France. Ensemble le Nomenclator. Paris, Jean Nicot, 1606.

RICHELET, Pierre. Dictionnaire de la langue Françoise Ancienne et Moderne. Augmenté de plusieurs additions d'histoire, de grammaire, de critique, de jurisprudence, et d'une liste alphabétique des auteurs et des livres cités dans ce dictionnaire. Tome Premier. Amsterdam, Libraires de la Compagnie d'Amsterdam, 1732.

ROUSSEAU, Jean-Jacques. Dernière réponse de Jean-Jacques Rousseau [à M. Bordes]. Discours sur les sciences et les arts. Versão on line: classiques.uqac.ca. ; acesso em 4 fevereiro de 2015.

SANTOS, Milton. Pensando o Espaço do Homem. São Paulo, Hucitec, 1982, 67p.

SANTOS, Milton. A Metamorfose do Espaço Habitado. São Paulo, Hucitec, 1988, $125 \mathrm{p}$.

SANTOS, Milton. A redescoberta da natureza. São Paulo, FFLCH-USP, Aula Inaugural, em 10 de março de 1992. Disponível em http://www.scielo.br/scielo.php?pid=S010340141992000100007\&script=sci_arttext; acesso em 19 novembro 2010.

TONNELAT, Émile. Kultur. Histoire du mot, évolution du sens. In: Civilisation: le mot et l'idée. Comunicação na Primeira Semana Internacional de Síntese. Paris, La Rennaissance du Livre, 1930, 142p.

TRÉVOUX. Dictionnaire universel françois et latin, vulgairement appelé Dictionnaire de Trévoux : contenant la signification et la définition des mots de l'une et de l'autre langue. Tome 2. Paris, Compagnie des Libraires Associés, 1771, $1000 \mathrm{p}$.

TYLOR, Edward B. Primitive culture. London, Murray, 1920, 524p. 
UNESCO. Recommandation concernant la sauvegarde de la beauté et du caractère des paysages et des sites. Actes de la Conférence générale. Résolutions. $12^{\mathrm{e}}$ session, Paris, 1962, p. 141-146.

UNESCO. Convention concernant la protection du patrimoine culturel et naturel. Adoptée par la Conférence Générale à sa dix-septième session, Paris, 16 novembre 1972. Disponível em http://unesdoc.unesco.org/; acesso 7 de abril 2000.

UNESCO. Conferencia Mundial sobre Políticas Culturales. México, 1982. Disponível em www.unesco.org; acesso 7 de abril 2000.

UNESCO. Recommandation concernant la sauvegarde des ensembles historiques ou traditionnels et leur rôle dans la vie contemporaine. In : Actes de la Conférence Générale. Dix-neuvième session. Annexe 1. Nairobi, 25 octobre- 30 novembre 1976, p. 21-29. Disponível em http://unesdoc.unesco.org/; acesso 7 de abril 2000

UNESCO. World heritage. Cultural Landscapes. Unesco-Icomos Documentation Centre, Disponível em http://unesdoc.unesco.org/; acesso 10 fevereiro 2009.

UNESCO. Paysages culturels. Disponível em whc.unesco.org. Acesso em 19 de abril de 2013.

VIRGILE. Géorgiques. Tradução para o francês de Jacques Delille. Paris, L. G. Michaud, 1819, 64p.

VOLTAIRE (1749). Les lois de Minos. Paris, Editions du Théâtre Classique, 2008, 49p.

VOLTAIRE. Oeuvres Complètes. Tome 5 (precedido pela Vie de Voltaire de Condorcet). Paris, Garnier Frères, 1877, 610p.

VOLTAIRE. Lettres philosophiques. Paris, Editions Princeps, 1734, 61p.

Margareth Afeche Pimenta

Arquiteta e Urbanista formada pela Universidade de São Paulo. Mestre em Planejamento Urbano e Regional pela Universidade Federal do Rio de Janeiro, Doutora em Geografia pela Universidade Paris IV-Sorbonne e Pós-Doutora pela Universidade de La Rochelle - França (Bolsa Capes). Atualmente é professora do Curso de Arquitetura e Urbanismo e da Pós-Graduação em Geografia da Universidade Federal de Santa Catarina. Coordenadora do Núcleo Cidadhis (Ufsc, CNPq) desde 1994.

UFSC, Centro Tecnológico, Departamento de Arquitetura. Campus

Universitário - Trindade

88040-900 - Florianopolis, SC - Brasil

E-mail : afeche@arq.ufsc.br

Recebido para publicação em outubro de 2015.

Aceito para publicação em janeiro de 2016. 